\title{
Editorial
}

\section{Frames and contestations: environment, climate change and the construction of in/justice}

Frames matter. They bring into view, interpret and - in a significant sense materialize bring into mattering - a set of assumptions, interpretations and practices of circumscription that shape (and interact with), as Gitlin puts it, 'what exists, what happens and what matters'. ${ }^{1}$ Moreover, frames matter for law. They determine the conditions under which problems are apprehended by law, and thus can influence the assertion of authority, jurisdiction and institutional responsibility over particular issues. ${ }^{2}$

Frames are central to this issue of the Journal of Human Rights and the Environment, their significance is apparent, overtly or tacitly, in each contribution. The frames discernible in the contributions are dynamic, emergent, and contested by counter-frames. It is clear that frames can take hegemonic and counter-hegemonic positions depending on their location in the emergent energies and contestations at stake in the field in which they function as shape-givers. Frames signal intensities of both focus and of action/inaction, and it seems clear that every framing inevitably involves selection, if not pre-selection - and in that, represents an exercise of power.

Contestation, between frames, between the ideological commitments that can underwrite them, between communities and movements both semiotic and material, are also present in this issue. Contestation perhaps inevitably underwrites key contemporary tensions surrounding the dense entanglements between humans and non-humans and convergent and divergent forces, energies and futures in the climate-pressed posthuman ecology of the Anthropocene.

In 'Contesting human rights and climate change at the UN Human Rights Council', M Joel Voss is explicit about the centrality and power of framing - and of contestation - in his analysis. The context for Voss's analysis is provided by discussions concerning the relationship between human rights and climate change at the UN Human Rights Council. Noting how hotly contested the issues are and how fraught the discussions become, Voss conducted participant observation of climate change resolutions at the Council between 2006 and 2019 in order to expose the rival framings of climate change enlivened in the discourses of state participants. Drawing on Payne's work on framing, persuasion and norm-contestation, Voss conceptualizes frames in a way that implies, to our mind, their operation as modes of organizing power: they provide, after all, 'a singular interpretation of a particular

1. T Gitlin, The Whole World is Watching: Mass Media and the Making and Unmaking of the New Left (University of California Press, Berkeley 1980) 6.

2. S Dehm, 'Framing International Migration' (2015) 3(1) London Review of International Law 133, 137. 
situation [which then indicates] appropriate behaviour for that context' ${ }^{3}$ Frames, Voss continues,

give 'meaning to and indicate how to interpret events and objects within discourse. They can range from adjectives describing the object itself to the context of discussion about the object'. ${ }^{4}$ Frames create shortcuts to help explain complex situations and to 'mobilize consensus'. 5

Frames, in other words, reduce complexity to imaginable horizons of meaning in order to forge some kind of convergent purpose or action. Voss identifies three dominant frames shaping the primary arguments presented at the Human Rights Council. These are, respectively, equity and development; climate change as being either a problem for human rights or a source of human rights obligations; and the third framing, which centres upon the mandate of the Council to discuss climate change as a human right. Within each of these framings, Voss suggests, lie further framings. Frames thus emerge from the analysis provided by Voss as multilayered and marked by dynamic tensions - contestation is fierce (particularly between Global North and Global South), and framing proves to be decisively important when affective power (as in the UN Human Rights Council) relies on discourse rather than legal coercion to achieve outcomes.

One powerful source of framing, of course, is ideology.

At one point in his argument, Voss notes (drawing on Dunlap) ${ }^{6}$ that the power of contemporary counter-framing aimed at environmentalism by the 'American Conservative Movement' concentrates on the perceived threat of environmentalism to 'the American way of life'. Voss argues that such anti-environmentalist frames, exported 'from the US to other parts of the world, [are] making it more difficult for climate change advocates to win over fence sitters'. 7 Thus, as Voss notes, '... frames travel'.

The transnational movement of anti-environmentalist frames makes all the more urgent the scrutiny of US Conservative climate denial discourses by Gavin Byrne in 'Climate change denial as far-right politics: how abandonment of scientific method paved the way for Trump'.

Byrne's central argument is that the form of argument deployed by the climate change denial movement in the US closely resembles the form of argument deployed by Nazi Germany with regard to the construction of Nazi racial definitions. Both arguments, Byrne suggests, involve a rejection of scientific method while simultaneously continuing to assume the instrumentalist reliability of science in the service of its own ends. Rejection of scientific method, argues Byrne, is intrinsically compatible with far-right politics as a 'philosophy of prejudice'. Climate denialism - prevalent in the US - has, Byrne argues, contributed to the conditions inviting a post-fact US Presidency, such as that of Donald Trump.

3. R Payne, 'Persuasion, Frames, and Norm Contestation' (2001) 7 European Journal of International Relations 39.

4. J Broadbent, J Sonnett, I Botetzagias et al., 'Conflicting Climate Change Frames in a Global Field of Media Discourse' (2016) 2 Socius: Sociological Research for a Dynamic World 4. 5. M Finnemore and K Sikkink, 'Taking Stock: The Constructivist Research Program in International Relations and Comparative Politics' (2001) 4 Annual Review of Political Science 409.

6. R Dunlap, 'Climate Change Skepticism and Denial: An Introduction' (2013) 57 American Behavioral Scientist 691-8.

7. Citing J Painter and T Ashe, 'Cross-National Comparison of the Presence of Climate Skepticism in the Print Media in Six Countries, 2007-10' (2012) 7 Environmental Research Letters 1. 
The gradually less rational framings of science traced by Byrne, and involved in the ideological trajectory of climate denial and of Nazi racial politics, ultimately operate in the service of a radical contestation of science - and empirical evidence - itself. The situatedness of these framings in their respective constitutional formations, however, is where Byrne draws a careful distinction between the conditions leading to the Nazi overthrow of the Weimar Republic and the conditions pertaining in the contemporary US constitutional landscape. The institutional interdependencies and structural arrangements holding democracy in place in the US are more resilient and multilayered than were those protecting the Weimar Republic in the 1930s. However, warns Byrne, while US institutional safeguards are more democratically resilient and thus likely to resist a short-term attack on environmental protection, the 'slow erosion of democratic norms by the Trump administration' represents a threat, particularly in an age of 'post-truth politics'. Ultimately, however, it is lived experience itself that provides a reality check: 'eventually, somewhere, someone will have to live with the reality [of climate change]. Therein, ultimately, lies hope ...' '.

Patterns of contestation between framings - and framings of contestation itself also emerge in Sabrina Cardenas and Esteban Angulo's 'Human rights vs. eco-justice: conflicts and other futures in urban open spaces in Cali, Colombia'. This article explores interactions between human rights and eco-justice in urban open spaces, primarily through on-site observation of dynamics in three iconic parks in Cali, Colombia. The fundamental underlying tension identified - as is so often the case - is a conflict between the ontological grounding of frames: anthropocentrism, in the case of human rights, and eco-centrism, in the case of eco-justice. Despite both frames being given significant normative space and expression in the laws of Colombia, the structural and material order foregrounding human rights means that, in reality, eco-justice is frequently undermined by human rights themselves. Such realities have, of course, intensely material implications for the entanglements of human and non-human life in the parks. The authors explore the implications of just three: defaunation; the proliferation of 'urban heat islands' and their impact on plant life in particular; and increased local pollution - this last set against global climate warming. Predictably, perhaps, in the parks studied, the dynamics at work in the entanglement between laws, framings, needs, contestation and praxis end up intensifying the influence of the dominant 'anthropocentric juridical model, mediated by capitalist interests'. Calling for a move away from a mono-discursive construction of human rights towards a multi-disciplinary convergence of insights and contributions, the authors argue for a more radical, eco-just and inclusive way of thinking and acting. Such an approach, they hope, might give meaningful impact to the fact that human beings, non-humans, ecosystems, the economy, nature, and more, is a commons and should be celebrated and defended by a deepening aspiration for human and non-human co-flourishing.

In her contribution, 'Climate change and displacement: protecting "climate refugees" within a framework of justice and human rights', Sumudu Atapattu interrogates how different conceptual frames might offer tools for responding to the urgent problem of climate displacement. She identifies a number of challenges in addressing climate-change displacement, including the multi-causal and complex drivers of human mobility, the fraught role of violence in the climate-migration nexus and the unique and distinctive legal questions, including of sovereignty, territory and nationality, raised by the potential loss of small-island states. In this context, terminology is not neutral; indeed, the choices regarding the different terms used to name and construct those who have been, or risk being displaced, carry immense political stakes. 
The legal terminology of 'political refugees', the discursive invocation of 'climate refugees' or the technical vocabulary of 'planned migration', all draw on and enliven different frames that make visible or obscure different aspects of complex realities. Atapattu canvasses a number of recent developments that have sought to respond to the pressing urgency, complexity and nuances of climate migration - including the Taskforce on Climate Displacement, the Global Compact for Safe, Orderly and Regular Migration, the Sendai Framework for Disaster Risk Reduction, and the Nansen Initiative and the Platform for Disaster Displacement - and identifies their numerous gaps, flaws and oversights.

In order to remedy these legal lacunas, Atapattu considers how emerging and existing conceptual frameworks might enable more comprehensive and just legal responses. She suggests that the principles of dignity and of the universality and indivisibility of human rights could provide important frameworks to protect the rights of displaced peoples, or indeed all those who are disproportionately affected or especially vulnerable to climate change, since they emphasize the rights of 'all people/s no matter who they are or where they come from', regardless of whether they are within their country of nationality or have been forced to enter another country. Drawing on different conceptualizations of environmental justice and environmental racism, Atapattu shows how these frames can help make visible the injustice inherent in the disproportionate vulnerability to climate displacement of racialized and poor communities. Such frames, she shows, can 'offer a lively, wide-ranging set of approaches to a justice-based response to climate change, and in particular to the disparities in its creation and implications for vulnerable communities'. Moreover, Atapattu suggests that coupling different conceptualizations of climate justice with principles that speak to differentiated obligations - such as the common but differentiated responsibilities and the polluter pays principles - could provide the basis for a comprehensive set of guidelines for informing state responses to climate displacement. Despite the dire predictions about the scale of climate displacement, she ends on an optimistic note, hopeful that ' $[\mathrm{b}] \mathrm{y}$ planning ahead, we will be able to address the unacceptable protection gap relating to climate refugees and to minimize human suffering before we are faced with an unprecedented global humanitarian catastrophe'.

Finally, in 'The swarm that we already are: artificially intelligent (AI) swarming "insect drones", targeting and international humanitarian law in a posthuman ecology', Matilda Arvidsson conducts an analysis of insect swarming technologies in military technology. Arvidsson specifically draws on critical environmental law (CEL), to draw lessons for the theorization of international humanitarian law (IHL). Arvidsson notes that while legal scholarship has extensively attended to drones, autonomous weapons systems and artificial intelligence, developments based on insect swarming technologies have been somewhat overlooked. To respond to this gap, Arvidsson, drawing partly on critical environmental legal scholarship, takes up Deleuze and Guattari's figurations of 'the swarm' and the 'war machine' to address the posthuman dilemmas now facing international humanitarian law. Arvidsson, like CEL scholars, argues that the human needs to be folded into a rich posthuman/'itarian' legal ordering of becoming. A posthumanist, or promisingly materialist, turn in IHL scholarship is as fundamental a need as the more complex forms of eco-just de-centring of the human in environmental law and human rights for the Anthropocene. Tracing a central tension, in which far from "dispersing the human from its central position in the "targeting loop", the increased interest in insects for commercial and warfare purposes is an intensification of transhumanist desires and an acceleration of late capitalism', Arvidsson calls, ultimately, for a new 
framing - based in a new onto-epistemic commitment to 'becoming swarm': embracing a minoritarian, critical position in the search for new forms of justice beyond binary structures in which 'man' emerges as the Promethean centre. This is a move, as Arvidsson suggests, drawing on Braidotti, that confronts questions about a 'simultaneity of being in the world together [that] defines the ethics of interaction with both human and non-human others' ${ }^{8}$ - framing questions of life and death for life beyond 'humanity' as such.

The patterns of framing, discourse, ideology and the materialities of conflict, swarming, migrating, and the entangled dynamics of struggles for eco-just ways of human-non-human relationality will not be new to readers of the Journal of Human Rights and the Environment. The frames and contestations at the heart of this issue represent well-rehearsed patterns of the imposition of life and death and their counter-movements: capitalist anthropocentrism (whether in the parks of Cali or the military war machine), its closely related Global North-Global South postand neo-colonial struggles (whether over climate migration, the relationship between climate change and human rights, or the Conservative climate denialisms fed by a fear for the 'American way of life'), and the urgent general need to develop critical, adaptive legal responses to the complex posthuman ecology of the Anthropocene. It seems clear that none of these patterns are fading in importance for analysts of the 'trouble' we are all now in - and which we urgently need to find ways to 'stay with'.?

Anna Grear Editor in Chief, Professor of Law and Theory, Cardiff Law School

Julia Dehm

Co Editor in Chief, Lecturer, La Trobe Law School

8. $\quad$ R Braidotti, The Posthuman (Polity Press, Cambridge 2013) 169.

9. D Haraway, Staying with the Trouble: Making Kin in the Chthulucene (Duke University Press, Durham, NC 2016). 